\title{
Práticas inclusivas na rede de atenção à saúde mental: entre dificuldades e facilidades
}

\author{
Inclusive practices in the mental health network: between difficulties and facilities
}

\author{
Elisângela Braga de Azevedo ${ }^{1}$, Maria de Oliveira Ferreira Filha ${ }^{2}$
}

\begin{abstract}
RESUMO
Objetivo: Identificar facilidades e dificuldades dos profissionais que atuam na rede de saúde mental em desenvolver práticas de inclusão social com os portadores de transtornos mentais.

Materiais e Métodos: Trata-se de uma pesquisa empírica, de natureza descritiva - interpretativa e qualitativa, realizada na rede de cuidado em saúde mental do município de Campina Grande/Paraíba/Brasil com 19 profissionais, de junho a julho de 2010. O material empírico foi analisado através da técnica de análise de conteúdo tipo categorial temática, tendo obedecido à resolução 196/96 do Conselho Nacional de Saúde.

Resultados: Dentre as dificuldades, os recursos financeiros, materiais e estruturais apresentam-se como um fator que impede avanços na efetivação da inclusão social dos usuários, sendo necessárias estratégias intersetoriais. $O$ preconceito e o estigma representa um desafio na atenção psicossocial. Como facilidades, destacam-se a disponibilidade dos profissionais para trabalhar com esse segmento, além da formação em educação permanente que têm possibilitado trocas de saberes, sedimentando a interdisciplinaridade necessária para o processo de trabalho em equipe.

Conclusão: Nesse contexto, há necessidade de cuidado por parte dos gestores frente às dificuldades identificadas, uma vez que, tal fato pode interferir diretamente no cuidado que vem sendo oferecido aos usuários. Contudo, as facilidades encontradas nesse estudo ultrapassam as fronteiras do cuidado em saúde mental, fato que consolida a reforma psiquiátrica, mesmo que de forma gradativa nesse país.
\end{abstract}

Palavras-chave: enfermagem; serviços de saúde mental; saúde mental.

\begin{abstract}
Objective: This study aimed to identify facilities and difficulties of professionals working in the mental health network to develop practices of social inclusion with mental disorder patients.

Materials and Methods: This is an empirical research, with a descriptive nature - interpretive and qualitative, performed in the mental health care network of the municipality of Campina Grande/Paraiba/Brazil with 19 professionals, from June to July 2010. The empirical material was analyzed by using the content analysis technique, thematic and categorical type, in accordance to the resolution 196/96 of the National Health Council.

Results: Among the difficulties, the financial, material and structural resources appeared as a factor that impedes progress in the consolidation of the users' social inclusion, being necessary intersectoral strategies. The prejudice and the stigma represent a challenge in the psychosocial attention. As facilities, stand out the professionals availability to work with this segment, besides the training in continuous education that has allowed exchanges of knowledge, basing the interdisciplinarity required for the process of team work.

Conclusion: In this context, there is a need for caution from the managers facing the difficulties identified, since this fact can interfere directly in the care that is being offered to users. However, the facilities found in the study, beyond the borders of mental health care, is a fact that consolidates the psychiatric reform, even in a gradually way in this country.
\end{abstract}

Keywords: nursing; mental health services; mental health.

\footnotetext{
${ }^{1}$ Enfermeira. Doutoranda em Enfermagem pelo Programa de Pós-Graduação da Universidade Federal da Paraíba (UFPB). Professora do Departamento de Enfermagem da Faculdade de Ciências Médicas de Campina Grande, PB.

${ }^{2}$ Enfermeira. Doutora em Enfermagem pela Universidade Federal do Ceará. Professora Adjunto IV da UFPB.
} 


\section{INTRODUÇÃO}

Ainda no século XX, mais precisamente entre 1970 e 1980 a busca pela transformação da saúde mental começa a ser uma realidade na política de saúde pública brasileira, na qual a luta por reforma no âmbito da saúde mental não se deu de modo desvinculado da luta pela reforma sanitária. Concomitante a VIII Conferência Nacional de Saúde, realizou-se dois eventos que marcaram o movimento em prol da transformação da assistência psiquiátrica brasileira: a I Conferência Nacional de Saúde Mental e o II Encontro Nacional de Trabalhadores em Saúde Mental, culminando com o que se almejou chamar de Reforma Psiquiátrica Brasileira ${ }^{1,2}$.

Outro avanço impulsionador da reforma psiquiátrica foi a aprovação da Lei 10.216 no ano de 2001, cuja autoria foi do Deputado Paulo Delgado. Tal lei dispõe sobre a extinção progressiva dos manicômios e sua substituição por novas modalidades de atendimento, tais como: hospitais-dia, Centros de Atenção Psicossocial (CAPS) - e Núcleos de Atenção Psicossocial (NAPS), enquanto regulamentam as internações psiquiátricas compulsórias, tornando-se um marco na história da psiquiatria brasileira, por envolver, em sua proposta, profissionais da área de saúde, usuários e familiares ${ }^{1-2}$.

Para tanto, isso só foi possível em decorrência da II Conferência Nacional de Saúde Mental (CNSM), dos fóruns e das discussões fomentados pelo Movimento Antimanicomial e da Declaração de Caracas, na qual rompeu o silêncio dos governantes e das políticas de saúde em relação à saúde mental ${ }^{3}$. Em 2001, foi realizada a III CNSM, tendo como tema central das discussões: "Cuidar, sim. Excluir, não", proposto pela Organização Mundial de Saúde (OMS). Esta conferência tornou-se um foro privilegiado, pois discutiu o financiamento das ações de saúde mental, a fiscalização da rede hospitalar psiquiátrica. O ritmo de implantação dos novos serviços extra hospitalares deu suporte a desospitalização de pacientes com longo tempo de internação e a formação de recursos humanos, entre outras providencias ${ }^{4}$.

Com isso, toda uma rede de cuidado em saúde mental foi sendo gradativamente construída para atender a demanda de usuários, criadas a partir da desinstitucionalização e desospitalização dos chamados manicômios, e para tanto, foram criados NAPS, CAPS, residências terapêuticas, emergências psiquiátricas e leitos em hospitais gerais e, posteriormente os Centros de Convivência e Cultura que foram implantados para oferecerem suporte à rede de cuidado em saúde.

$\mathrm{Na}$ contemporaneidade os serviços substitutivos da reforma psiquiátrica têm como principal objetivo a inserção dos usuários nos espaços sociais, contudo, os profissionais ainda enfrentam dificuldades para o seu desenvolvimento. Dentre as dificuldades presentes no atual processo de trabalho dos profissionais, está o desafio de romper com o modelo hospitalocêntrico, configurados pela assistência psiquiátrica que priorizou, por anos, a assistência curativa.

Entretanto, questões como a inclusão social do portador de transtorno psíquico não tem sido tarefa fácil, isso porque, a literatura sobre o tema mostra que:

Desde os primórdios dos tempos, o louco já era estereotipado e taxado como demônio, visto como um incômodo para a sociedade vigente, pois era um indivíduo sujo, estranho, que agia diferente das pessoas normais, então, excluído. Desse modo, o padrão de comportamento estabelece aquele que é adequado ou não, e daí surgem todos os preconceitos e estigmas $^{5: 126}$.

É importante enfocar que falar de cidadania e direitos não basta, como também, aprovar leis não é suficiente, pois essas não determinam que as pessoas sejam cidadãs e sujeitos de direito por decreto. "A construção de cidadania diz respeito a um processo social e, tal qual nos referimos no campo da saúde mental e atenção psicossocial, um processo social complexo. É preciso mudar mentalidades, mudar atitudes, mudar relações sociais" ${ }^{\text {6:71. }}$.

Por outro lado, algumas facilidades podem ser visualizadas em alguns serviços. Esse estudo realizado em 2004 no município de São Paulo com os profissionais dos serviços de Álcool e Drogas, já revelava que os profissionais que atuam na atenção psicossocial mostram-se motivados em trabalhar com as pessoas em situação de sofrimento psíquico, por se sentirem emocional e afetivamente recompensados e por tratar-se de um modelo de atenção substitutivo ao modelo psiquiátrico, em que houve o desligamento dos 
ambulatórios de psiquiatria e favoreceu a construção de locais próprios para o desempenho das atividades peculiares destes serviços ${ }^{7}$.

Segundo o Ministério da Saúde (MS), desde 2002, foram desenvolvidas ações permanentes relativas à formação de recursos humanos no campo da Saúde Mental e Reforma Psiquiátrica para trabalhadores do SUS. Estas ações foram contempladas no Programa Permanente de Formação de Recursos Humanos para a Reforma Psiquiátrica e apresentavam como prioridades as seguintes ações: Núcleos de Formação em Saúde Mental para a Rede Pública com incentivo à sua criação, financiamento e apoio às atividades desenvolvidas, por meio de convênios entre o MS e Instituições Formadoras, em especial com Universidades Federais, além de Municípios e Estados ${ }^{8}$.

Para tanto, pergunta-se: Quais as facilidades e dificuldades de desenvolver práticas de inclusão social os profissionais que atuam na rede de saúde mental estão apresentando? Assim, objetivou-se identificar facilidades e dificuldades dos profissionais que atuam na rede de saúde mental em desenvolver práticas de inclusão social com os portadores de transtornos mentais no município de Campina Grande, Paraíba, Brasil. Este artigo trata-se em um recorte da dissertação de mestrado, intitulada: Rede de Cuidado em Saúde Mental: Tecendo Práticas de Inclusão Social.

\section{MATERIAIS E MÉTODOS}

Trata-se de uma pesquisa empírica, de natureza descritiva - interpretativa e qualitativa, realizada na rede de cuidado em saúde mental do município de Campina Grande, Paraíba, Brasil.

A pesquisa foi realizada com 19 profissionais, escolhidos intencionalmente, segundo os critérios de inclusão: 1) ser profissional atuante na rede com tempo de serviço maior ou igual há um ano, 2) estar desenvolvendo práticas inclusivas para os portadores de transtornos mentais.

O material empírico foi produzido através de um roteiro de entrevista semiestruturada, contemplando as seguintes questões: (1) Existe alguma dificuldade em realizar prática de inclusão social com os usuários?
(2) Quais facilidades você encontra para realizar práticas inclusivas no serviço?

A coleta do material empírico ocorreu no mês de junho a julho de 2010. Todas as entrevistas foram gravadas e posteriormente transcritas em sua literalidade, tendo sido categorizadas por: homogeneidade, exaustividade, exclusividade, objetividade e adequação ou pertinência. Desse modo, o material empírico foi analisado através da técnica de análise de conteúdo categorial temática ${ }^{9}$.

O estudo foi desenvolvido de acordo com os aspectos éticos da pesquisa, envolvendo seres humanos recomendados pela resolução 196/96 do Conselho Nacional de Saúde do Ministério da Saúde, que aborda os deveres e direitos do pesquisador e sujeito. A mesma foi submetida à apreciação do Comitê de Ética em Pesquisa (CEP) do Hospital Universitário Lauro Wanderlei (HULW) da Universidade Federal da Paraíba (UFPB) que emitiu parecer favorável em 01/07/2010, segundo protocolo CEP/ HULW nำ 264/10.

\section{RESULTADOS}

Desde o movimento da reforma psiquiátrica, o MS tenta avançar na efetivação de práticas inclusivas na rede de serviços substitutivos disseminadas por todo o país, porém, ainda se depara com algumas dificuldades que têm contribuído para que essas iniciativas não se concretizem. Por outro lado, alguns municípios brasileiros têm mostrado avanços concretos na realização dessas práticas que são subsidiadas por algumas facilidades peculiares. Nesta perspectiva, emergiu duas categorias temáticas, descritas abaixo:

\section{Dificuldades na promoção de práticas inclusivas}

Uma das propostas da reforma psiquiátrica é o resgate da cidadania das pessoas com transtornos mentais, existentes nos espaços territoriais de todos os serviços. É sob esse prisma que um dos objetivos desse estudo, foi identificar dificuldades dos profissionais atuarem com práticas de inclusão social no município, para que, através destes achados, novas soluções fossem estabelecidas. Sob esse enfoque, emergiram as seguintes subcategorias: 


\section{Recursos financeiros/materiais}

A precariedade do atendimento oferecido à população nos serviços públicos de saúde mental relaciona-se, às tendências da política de saúde adotada nos últimos vinte anos. Contudo, em 2005 alguns progressos foram identificados, quando o MS implantou uma linha específica de incentivos financeiros para os municípios que desenvolvessem atividades de inclusão social pelo trabalho para pessoas com sofrimento psíquico ou com transtornos decorrentes do uso de álcool e outras drogas. Pela primeira vez, iniciativas como essas, passaram a receber Recursos Federais ${ }^{3}$.

Posteriormente, o programa de inclusão social pelo trabalho foi assumido pelo Ministério do Trabalho e Emprego (MTE) e MS; sendo assim, tais instituições passaram a articular definitivamente a saúde mental e a economia solidária na discussão da complexa problemática da inclusão desses portadores ${ }^{3}$. Sente-se, contudo, a necessidade de avanços, pois as fragilidades identificadas nas falas dos entrevistados quanto ao financiamento, possibilitam que a reforma psiquiátrica não se consolide com plenitude nos serviços, como constatado a seguir:

"A dificuldade [...] da própria gestão quando a gente esbarra no material, [...] para ser utilizado na geração de renda, a gente tem o ciclo, [...] utiliza o material, [...] gera renda, e a gente não tem o retorno do material, entendeu. [...] Essa é uma dificuldade grande [...]". (P. 01).

"[...] a gente não tem financiamento do Ministério da Saúde, mais foi uma das coisas que foi discutida nessa quarta conferência [Nacional de Saúde Mental] lá em Brasília, segundo [a profissional $A$ ] nos passou. $E$ o financiamento é onde a gente vai ter mais respaldo para divulgação e oferecer mais cursos, ter mais recursos, até humanos também [...]" (P.08).

"[...] é muito difícil falar do social e não falar [...] do recurso financeiro, [...], então assim, é curso, é ingresso a esse tipo de coisas, [...] o ônus do orçamento, para isso, nós não temos quase investimento [...] então a equipe trabalha com o dispositivo da rede, mas uma passagem, um material, tudo isso, é a equipe que tenta junta traçar meios para chegar até esse denominador comum, que é tentar inseri-lo na sociedade”. (P. 06).

"É com relação a recurso do governo, porque a gente se esforça para caramba aqui, sabe [...] temos uma estrutura legal, [...] só precisava dar uma melhorada nela, [...] que pudesse melhorar a qualidade de serviço $e$ trazer mais usuários para gente" (P. 16).

Verifica-se através das ideias acima que os recursos financeiros, materiais e estruturais, ainda representam um fator que dificulta avanços em práticas de inclusão social no município. Recursos que muitas vezes seriam utilizados na geração de renda, nas oficinas que são desenvolvidas nesses espaços, cujo objetivo é promover a melhoria da autoestima e favorecer o trabalho inclusivo.

Como visto, a intenção dos profissionais na disponibilização dos materiais ou mesmo na melhoria da estrutura física, seria para melhorar a qualidade da atenção à saúde oferecida aos usuários e seus familiares, porém os gestores municipais precisam de maior sensibilização, pois as falas dos entrevistados nos revelam que muitas ações só acontecem porque eles buscam meios próprios para sua efetivação.

Uma esperança para tal problemática foram os avanços nas discussões e negociações na IV Conferência Nacional de Saúde Mental, realizada em junho de 2010 em Brasília. O financiamento para saúde mental foi um dos temas contemplados nas discussões do Eixo I: Saúde Mental e Políticas de Estado, que propõe pactuar caminhos intersetoriais para garantir o financiamento, os recursos humanos, o modelo de gestão e o protagonismo social ${ }^{10}$.

O relatório final da conferência mencionada, precisa produzir progressos, pois o financiamento ainda representa, no nosso país, um entrave na consolidação do SUS e da reforma psiquiátrica. Delgado ${ }^{11}$ complementa essas ideias dizendo que embora algumas melhorias possam ter acontecido com a reforma psiquiátrica e com o SUS, em que os investimentos mais que dobraram para a saúde mental, estes ainda são insuficientes para responder as atuais necessidades das pessoas em situação de sofrimento psíquico. Para ele, o SUS gasta $2,7 \%$ do seu orçamento com saúde mental, mas é preciso ampliar esse 
orçamento para aproximadamente $4 \%$. Isto porque, a demanda de saúde mental afeta pelo menos $25 \%$ da população geral em algum momento da vida, e $12 \%$ ao longo de um ano.

Cabe observar, no entanto, que a gestão da saúde mental deste município precisa repensar estratégias de articulação com os demais gestores municipais, estaduais e federais para que esses recursos financeiros sejam garantidos, possibilitando investimentos na reabilitação psicossocial e avanços no processo da Reforma psiquiátrica.

\section{Preconceito da sociedade/família/profissionais}

Desde a antiguidade, a sociedade demonstra dificuldade em lidar com as diferenças entre pessoas e de aceitar os portadores de deficiência físicas e mentais nos espaços sociais. Contudo, a humanidade tem toda uma história para comprovar como o caminho dessas pessoas com transtornos mentais tem sido permeado por obstáculos, riscos e limitações, como tem sido difícil sua sobrevivência, desenvolvimento e convivência social.

É relevante que se mostre à sociedade o quanto ela cria problemas para os portadores, causando-lhes incapacidades e muitas desvantagens no desempenho de papéis sociais, seja através da restrição nos ambientes, nas políticas discriminatórias e suas atitudes preconceituosas que rejeitam as minorias, através dos seus discutíveis padrões de normalidade, dentre outros $^{12}$.

Os depoimentos a seguir revelam barreiras que têm dificultado progressos nas práticas de inclusão a que os serviços substitutivos se propõem:

"[...] a primeira dificuldade que a gente enfrenta é a questão dos tabus sociais, [...] A questão da cultura social [...] da doença mental que ainda é muito impregnada na sociedade, [...] as pessoas [...] têm dificuldade para aceitar o outro que tem problema mental, [...] lembrando que hoje é muito menor, nós já conseguimos espaços em entidades [...]". (P. 06).

"[...] uma das coisas aqui que a gente mais vê é a própria discriminação das pessoas que realmente [...] não aceitam [...], daí a gente tem que ter todo um trabalho para que [...] as pessoas, até os próprios familiares, que esses usuários são muito discriminados [...], não só adulto, [...] crianças [...] que fazem parte aqui do CAPS [...] das escolas. A gente vê [...] até por parte dos educadores que não têm um certo conhecimento [...]". (P. 10).

"O preconceito. A lei do preconceito prevalece muito, porque quando a pedagoga, ela ou alguém da equipe solicita as vagas, então a gente percebe [...] que existe: Ah, é usuário de drogas?... Mais aí, os outros [participantes do curso] [...] já vão saber que é usuário de drogas, já não vão querer participar também... [...]". (P. 12).

"[...] as pessoas do próprio convívio têm [...] algum tipo de medo, [...] nós estamos tentando mudar esse paradigma, de que o doente mental [...] seja agressivo, ele tenha uma hora em que a loucura possa chegar, e não é. [...] Isso é uma dificuldade, a própria população, porque o doente mental teve durante muito tempo [...] como sendo ameaçador à sociedade. [...] uma das dificuldades ainda é o povo achar que o doente mental é uma ameaça, [...] até os próprios funcionários, a gente tem dificuldade porque acham que não tem formação para tal [...]". (P. 13).

"A questão do preconceito [...] a sociedade ela é muito preconceituosa [...] principalmente quando se trata de pessoas que são usuários de drogas [...] essas pessoas realmente estão [...] afastadas [...] do vínculo social, [...] a dificuldade maior é a questão do preconceito mesmo, de discriminação por parte da sociedade em geral, tanto a própria família do usuário que muitas vezes [...] tem sofrido tanto com essa questão de lutar... com a questão da dependência, que aí eles terminam sendo excluídos, até mesmo da própria família, [...]". (P. 15).

No ponto de vista dos profissionais, o preconceito, os tabus, os estereótipos, a discriminação, e o estigma são fatores que têm dificultado o desenvolvimento de práticas de inclusão social, seja da sociedade, dos familiares ou mesmo dos próprios profissionais da rede que lidam com essas pessoas, mostrando que ainda temos muito a avançar na efetivação das políticas públicas direcionadas à Saúde Mental. É fundamental que ocorram momentos de sensibilização que 
possibilitem a desconstrução da concepção da loucura ainda vigente entre os profissionais e que ainda estão impregnados de um referencial conceitual que desfavorece a inclusão social.

Para fazer uma ruptura desses preconceitos, deve-se desconstruir conceitos arcaicos da doença mental, e possibilitar que as pessoas conheçam e, ao mesmo tempo, se relacionem com o sujeito em sofrimento psíquico e que, neste momento, estas se dirijam a ele enquanto pessoa e não às suas doenças, vislumbrando espaços terapêuticos que possibilitem escuta e acolhimento nas angústias e experiências vividas, em espaços de cuidado que produzam a sociabilidade e a subjetividade do sujeito, construindo, desta forma, estratégias efetivas de cidadania e participação social ${ }^{6}$.

Geralmente a pessoa com transtorno mental é tratado pela sociedade e/ou familiares, de modo discriminatório, preconceituoso, devido ao estigma que a loucura impõe sobre ela. Nos CAPS existe a possibilidade dos profissionais iniciarem um processo de desconstrução deste estigma, uma vez que, estes discutem, refletem e atuam de modo que sua conduta não seja de exclusão ${ }^{13}$.

Em 2004 foi realizado um estudo que avaliou a atuação do profissional no CAPS do Estado do Espírito Santo, tendo comprovado em seus achados que as condições gerais de trabalho na saúde pública constituem um fator que tende a comprometer o engajamento dos técnicos nas ações que deveriam ultrapassar os limites dos muros dos CAPS. Os pesquisadores argumentam que a intervenção no campo social, tornou-se o maior desafio enfrentado pelos profissionais que atuam na atenção psicossocial ${ }^{14}$.

Entendeu-se que os serviços substitutivos trabalham com um enfoque inclusivo, desse modo, os profissionais que atuam nesses serviços estão sempre buscando parcerias com outros setores da rede de serviços do município que incluam os usuários nos espaços sociais, sendo essenciais que se concretizem ações intersetoriais que os integrem na escola, no trabalho, no lazer, dentre outros. Nas próximas falas alguns profissionais e instituições ainda mostram-se despreparadas para promover essa inclusão:
"[...] a outra dificuldade é [...] nos articularmos [...] com outras instituições na perspectiva de comprovarmos que o nosso usuário tem essa possibilidade. [...] porque o usuário uma vez sendo usuário da saúde mental é um usuário limitado que está [...] cotado para ser [...] periciado, para ser beneficiado. [...] para ser até curatelado. [...] Normalmente as instituições tem essa visão, por quê? Porque elas não conhecem a realidade do trabalho que a gente desenvolve no CAPS, eles ainda atribuem à saúde mental a questão hospitalar [...]" (P. 14).

"A interlocução entre um serviço e outro, porque a gente tenta fazer as referências [...] contrarreferências [...], só que, [...] da outra parte não existe [...] tem essa dificuldade de aceitar [...] quando a criança não é perfil do CAPS, [...]" (P. 17).

"A maior dificuldade que a gente encontra é o preconceito que existe, [...], nos profissionais das outras instituições na hora de receber, porque quando a gente se identifica dizendo que é de um CAPS, que atende crianças e adolescentes com transtorno mental, sofrimento psíquico, existe a ideia, ainda um pouco preconceituosa, de como se trabalhar com esse público, com essa clientela, como se o trabalho fosse completamente diferente [...] fosse necessário haver uma capacitação antes de estar acolhendo [...]". (P. 18).

"[...] essa questão da preparação das outras instituições, a escola, por exemplo, é a nossa maior dificuldade [...] a gente se depara com o discurso do professor de dizer que não está preparado e aí a gente fica sempre se perguntando? - eles não vão está preparado até quando? Porque o CAPS é mais recente do que a inclusão da educação [...]". (P. 19).

Os entrevistados revelam que ainda existem instituições e profissionais resistentes para desenvolver práticas de inclusão social para pessoas em situação de sofrimento psíquico. No ponto de vista dos profissionais, o fato dos professores ainda apresentar o discurso de não estarem preparados para trabalhar com a saúde mental, tem sido um fator considerado grave e preocupante, isto porque, o processo de discussão da inclusão na escola, iniciou bem antes que na área da 
saúde.

Percebeu-se que, a aceitação social das pessoas portadoras de deficiências mentais e físicas na escola tornou-se uma luta de longa data no país. De acordo com a UNESCO ${ }^{15}$, foi em 1990, através da Declaração Mundial sobre Educação para Todos, que houve um maior estímulo de estudos na literatura educacional sobre inclusão na educação, tendo esse fato se tornado um ideal nas reformas e plataforma educacionais.

Incluir as pessoas com deficiências sejam, físicas ou mentais nas classes regulares não é simplesmente matriculá-las e oferecer acesso. Exige planejamento, recursos, sistematização e acompanhamento permanente. É um processo que, embora lento, tem um caráter transformador. Neste sentido, a escola precisa estar preparada para incluir os alunos com essas demandas no seu interior, haja vista os grandes benefícios que a educação traz para todos os cidadãos $^{16,17}$.

Cabe observar, no entanto, que as escolas do município de Campina Grande terão um grande desafio: tornar-se uma escola inclusiva, e desta forma, oferecer um ensino de qualidade e que respeite o direito de toda criança, garantido no Estatuto da Criança e do Adolescente (ECA), conforme observa-se no artigo $4 .^{\circ}$ descrito adiante:

É dever da família, da comunidade, da sociedade em geral e do poder público assegurar, com absoluta prioridade, a efetivação dos direitos referentes à vida, à saúde, à alimentação, à educação, ao esporte, ao lazer, à profissionalização, à cultura, à dignidade, ao respeito, à liberdade e à convivência familiar e comunitária ${ }^{18: 9-10}$

\section{Facilidades de se promover práticas inclusivas}

As facilidades dos profissionais da rede de atenção psicossocial realizar práticas de inclusão social foram relatadas através das seguintes subcategorias abaixo

\section{Apoio das instituições/profissionais}

Com base nos avanços que os profissionais que atuam na rede de cuidado em saúde mental desse município vêm alcançando com suas práticas inclusivas, alguns progressos foram encontrados no que tange o rompimento do preconceito dos profissionais $\mathrm{e}$ instituições para contribuírem com ações que favorecem a inclusão de pessoas em situação de sofrimento psíquico. As falas abaixo ilustram essa discussão:

"[...] hoje eu vejo que as pessoas estão mais interessadas, antes era uma coisa que ninguém nem queria trabalhar e hoje quando você chega nas escolas, você já encontra profissionais abertos, [...] para esse trabalho, [...], que querem estudar. Ah, eu vou demais! Então, vem para o estudo e isto ajuda bastante, [...] isso facilita, se numa escola você chega tem uma direção que é meio dura pra aceitar, aí tem profissional que já ajuda, [...] você pede para marcar um momento e você consegue [...] sensibilizar todo mundo, [...]". (P. 03).

"[...] a abertura que a gente encontra, [...] nas instituições que a gente vai, a gente vê que as pessoas, já estão abrindo mais a mente, no tocante a esse tema [...] eu imagino que as pessoas estão tendo mais cuidados, [...] eu acho que o fato de repente ter um vizinho, ou ter um parente [...] estão mais abertos, [...] mostrando mais interesse, estão incutindo mais essa questão e de certa forma aderindo, [...] a essa luta e até a história do não preconceito, [...]". (P. 09).

"[...] o apoio das instituições, quando a gente procura, quando vai se trabalhar lá, no caso o projeto saúde na escola, [...] as fontes a quem a gente se dirige e o apoio que nos dão, isso abre um leque muito grande que ajuda muito a tocar o barco para frente". (P. 11).

"As facilidades? Hoje em dia existe um movimento muito grande [...] existe uma abertura maior [...], ah! Eu não sei receber, eu não sei como trabalhar, ainda tenho um certo receio de como fazer isso, mas estou aberto a essa experiência, [...] então a gente vem encontrando, [...] uma certa facilidade nesse trabalho porque as pessoas têm se tornado mais receptivas, no sentido de querer colaborar com essa inclusão". (P. 18).

As falas relatadas acima revelam que muitos profissionais estão disponíveis para trabalhar com o segmento da saúde mental, buscando aprender e colaborar com o tratamento proposto, compreendendo assim, o processo da reforma psiquiátrica e aderindo ao não preconceito. Os entrevistados atribuem estes avanços ao movimento nacional de luta para a 
efetivação da inclusão social. Nesta perspectiva, evidenciou-se evolução e posturas mais receptivas e abertas para o trabalho com pessoas em situação de sofrimento psíquico. Tal afirmação contrapõe-se aos achados na categoria anterior, na qual esse emerge também como um fator dificultador, com isso, entendese que, embora se rompimento, tenha sido relatado por alguns profissionais, ainda é preciso avançar em políticas públicas que permitam sua expansão.

Especialização em saúde mental/capacitações/grupo de estudo

Diante dos avanços no SUS desde a década de 1990, com a promulgação das Leis Orgânicas de Saúde (Leis 8.080 e 8.142), e dos movimentos pela reforma psiquiátrica, o mercado de trabalho passa a exigir um profissional com um novo perfil, para atuar com essa demanda da saúde mental, criada a partir dos modelos substitutivos. Neste contexto, emerge a necessidade de educação permanente desses profissionais para que atuem com mais conhecimento e segurança na rede de cuidado em saúde do país.

Assim, as falas dos entrevistados relatam que os gestores municipais têm buscado momentos de ensino aprendizagem com frequência em Campina Grande, como visualizado a seguir:

"[...] a partir do momento que nós entramos para trabalhar na saúde mental [...] nós estamos vendo a facilidade [...] pelos seminários [clínicos], as orientações [...], a gente vai encontrando alguma forma de como lidar com essas pessoas, de sensibilizar. [...]. Semanalmente é o grupo de estudo, para estudar os casos clínicos e algumas supervisões com vários profissionais". (P. 10).

"[...] a grande facilidade que a gente tem é o incentivo, as capacitações que a coordenadora de saúde mental nos oferece [...] o fundamental, é o saber [...] através de cursos". (P. 13.).

"[...] essa abertura, [...] trabalhar a questão da família, nós temos a reunião da família, [...] Eventos relacionados à questão de saúde mental [...] como a gente teve uma marcha, um movimento nas ruas para tentar [...] mostrar as pessoas da sociedade o que é a saúde mental em Campina Grande, onde todos do serviço foram às ruas [...] para uma grande caminhada [...]" (P. 15).

"Eu acho que [...] os grupos de estudo, que facilita você de ter mais o domínio de determinadas situações, de entrar em contato com outros setores [...] com outras ações, para tentar ajudar no tratamento, no caso da criança, acho que, o estudo que a gente desenvolve faz você abrir o olhar e direcionar aquele tratamento $e$ aquela criança para alguma atividade. E o grupo de estudo ocorre, toda quinta-feira [...] de sete e meia as nove, sobre a criança e os cuidados com a criança, que está aberto para qualquer profissional [...]". (P.17).

"[...] a gente vem observando isso nas conferências, nos seminários que acontecem semanalmente, com a coordenação de saúde mental, nas reuniões intersetoriais, [...] nas supervisões [...], de casos clínicos. Então, existe essa prática [...] contínua de está fazendo esse elo intersetorial através dessas ações. $(P$. 18)".

Os entrevistados acima nos revelam que os gestores municipais têm motivado seus profissionais, através das capacitações, seminários clínicos, orientações, supervisões e grupos de estudo realizados semanalmente com representantes de toda a rede de atenção à saúde. Percebeu-se que, a partir do momento que os profissionais passam a atuar nesta área, logo se iniciam as capacitações, através de encontros semanais que ocorrem nas quintas feiras no CAPS Infantil (CAPSi) denominado de Centro Campinense de Intervenção Precoce Infantil, no turno da manhã e nos seminários clínicos que acontecem semanalmente, no mesmo local. Nesta oportunidade, profissionais experientes são convidados para ajudar os técnicos nas condutas clinicas de casos de difícil resolução para as equipes, tanto dos CAPS quanto da Estratégia Saúde da Família (ESF).

As reuniões técnicas, as supervisões de profissionais de apoio, as discussões de casos que possibilitam integração da equipe interdisciplinar e as reuniões semanais dos profissionais que atuam nesses centros, favorecem que estes tracem projetos terapêuticos individuais e coletivos mais efetivos, bem como, servem 
de leitura do processo de trabalho institucional, possibilitando revisões sistemáticas do projeto desenvolvido $^{19}$.

A história das capacitações na rede de saúde mental de Campina Grande está enraizada desde a sua construção.

Concomitante com a implantação de tais serviços foram contratados os profissionais selecionados para compor as equipes de atuação nos serviços. Sendo realizada capacitação durante três dias, com técnicos da Secretaria de Saúde do Município, da Secretaria de Saúde de Recife, e Assessores Técnicos do Ministério da Saúde, abordando temas como acolhimento, projetos terapêuticos, manejo de situações de crise, psicofarmacologia funcionamento dos CAPS, das Residências Terapêuticas e clínica de Reabilitação Psicossocial $^{20: 76}$.

Para o MS, o processo de formação de recursos humanos para atuar na saúde mental, desde 2002, mostra-se como prioridade, quando este órgão implantou o Programa Permanente de Formação de Recursos Humanos para a Reforma Psiquiátrica, visando incentivar, apoiar e financiar a implantação de núcleos de formação para esse setor. Isto através de parcerias com outras instituições formadoras como as Universidades Federais, os Municípios e os Estados ${ }^{3}$.

As especializações em saúde mental na atual conjuntura representam progressos que favorecem a qualidade na assistência oferecida aos usuários do sistema de saúde mental dos municípios brasileiros e, consequentemente, a inclusão social. Desta forma, elencou-se falas que revelam sua importância para a consolidação da intersetorialidade na rede de serviços de saúde, deste município, citada de forma recorrente:

\section{"[...] Essa parceria com a Universidade Federal com a} Prefeitura [SMS] de Campina Grande tem proporcionado essa integração das redes. [...] através da Especialização em saúde mental” (P. 05).

"[...] hoje tem uma realidade totalmente diferente, [...] hoje a gente vê os PSFs [profissionais] inseridos nas especializações, [...] se capacitando, mostrando interesse em trabalhar com esse segmento, [...]. Então, hoje a realidade já é diferente, já mudou [...] já tem outra cara [...]" (P. 09).
"[...] os profissionais hoje na saúde mental são pessoas capacitadas, através de vários cursos de capacitação e especialização, e é uma forma de haver essa integração desses setores [...] conhecer que todos estão no mesmo caminho, PSF [...] Atenção Básica, CAPS, Conselho Tutelar, para que juntos, conhecendo a problemática da saúde mental, estes possam ter estratégicas de poder enfrentar essa situação [...]“ (P.12)

“[...] a coordenação de saúde mental, há mais ou menos dois anos, ela tentou fazer essa parceria com a saúde da família, [...] e ai nós fizemos umas reuniões com as equipes, aonde nós fomos até eles $e$ convidamo-los para vir até a gente [...]. Quando, ela traz também os cursos, as capacitações [...] ela convida [...] a atenção básica pra participar, conforme nós estamos tendo agora, as especializações que foram abertas [...], para atenção básica, a coordenação tem tentado[...]" ( $P$. 14).

"[...] um dos facilitadores destes últimos tempos foram as especializações, que foram desenvolvidas, envolvendo outro segmento, outros equipamentos da rede como: equipes da UBSF, conselho tutelar, NASF, [...] o que a gente percebeu das pessoas que estão participando dessas especializações ou de um seminário clinico que a gente tem na quinta-feira, ela fica com um olhar diferente no caso dos encaminhamentos [...] também o programa de intervenção precoce que a equipe vai visitar a Atenção Básica, isso facilita meus encaminhamentos e nesta percepção das pessoas[...]" (P.19).

Os profissionais entrevistados revelaram que a especialização em saúde mental, proporcionou a articulação da rede de cuidado em saúde, integrando os serviços de saúde mental, o Núcleo de Apoio à Saúde da Família (NASF), a ESF, o conselho tutelar e demais serviços, favorecendo, desta forma, a construção das redes sociais e a integralidade do cuidado. Essas iniciativas têm possibilitado o rompimento de preconceitos, uma vez que, após essas capacitações alguns profissionais se mostraram abertos para trabalhar com o segmento da saúde mental, melhorando também, devido à criação de elos que se consolidam e 
promovem a inclusão dos usuários em cada território.

O primeiro Curso de Especialização em Saúde Mental realizado no município de Campina Grande ocorreu em 2007 e foi promovido pela Universidade Estadual da Paraíba (UEPB) em cooperação técnica com a Fundação Oswaldo Cruz (FIOCRUZ) com carga horária total de 360 horas. As aulas foram ministradas no Departamento de Psicologia da UEPB. Foram oferecidas 22 vagas para os coordenadores dos serviços e das coordenações estadual, regional e a municipal de Campina Grande; 3 vagas para professores da UEPB, nos cursos de Enfermagem, Serviço Social e Psicologia; e outras 25 para trabalhadores da Rede de Serviços Substitutivos da Saúde Mental ${ }^{20}$.

A segunda especialização em saúde mental foi viabilizada entre uma parceria da Prefeitura Municipal de Campina Grande e a UFCG, ocorreu em 2009 e 2010, tendo, também, favorecido a intersetorialidade e a interdisciplinaridade. Tal especialização objetivou integrar a rede de assistência à saúde, contemplando profissionais de todos os setores que prestam cuidado aos portadores de transtornos mentais, com os quais enfocamos: ESF, CAPS, NASF, Conselho Tutelar, Residências Terapêuticas e Emergências Psiquiátricas.

Sendo assim, esta pesquisa empírica revela que os gestores municipais, nesses últimos anos, têm treinado seus técnicos e possibilitado trocas de saberes entre os profissionais da rede de cuidado. Sobretudo, sabe-se que muito se tem a avançar, no que tange ao suporte necessário a todas as equipes da atenção básica, quanto ao seu treinamento/acompanhamento/suporte e matriciamento.

\section{CONSIDERAÇÕES FINAIS}

O estudo evidenciou facilidades peculiares na atuação dos profissionais que atuam na rede de saúde mental do município pesquisado em desenvolver práticas de inclusão social para os portadores de transtornos psíquicos, com isso, ressalta-se o rompimento de preconceitos, estereótipos e o estigma, seja dos profissionais dos demais setores da saúde e educação e/ou instituições, revelando que, alguns se mostram disponíveis para trabalhar com esse segmento, buscando aprender e colaborar com o tratamento proposto, compreendendo, deste modo, o processo da reforma psiquiátrica.

Faz-se a alusão, portanto, que tais avanços foram atribuídos ao movimento nacional de luta para a efetivação da inclusão social em que estas instituições e profissionais têm aderido ao desafio nos últimos anos, evoluindo e tornando-se mais receptivos e abertos ao trabalho. Outro fator positivo identificado foi o processo de formação de educação permanente e capacitação dos profissionais que atuam na saúde mental, tal acontecimento possibilitou trocas de saberes, sedimentando a interdisciplinaridade necessária para o processo de trabalho em equipe.

Entretanto, foi possível identificar que os profissionais que atuam na rede de cuidado em saúde mental ainda se deparam com dificuldades na efetivação de tais práticas inclusivas que divergem do modelo de cuidado proposto, merece destaque, os entraves nos recursos financeiros, materiais e estruturais que tem inviabilizado avanços. Isto porque, tais recursos são utilizados na geração de renda, nas oficinas, cujo objetivo é promover a melhoria da autoestima e favorecer o trabalho inclusivo.

Percebe-se também, a necessidade de se ampliar 0 número de equipes matriciais do CAPS a todas as equipes da ESF, essa fragilidade decorre, porque as atuais equipes dos CAPS não estão conseguindo oferecer o apoio necessário a todos profissionais no que se refere ao treinamento, acompanhamento e suporte.

Foi possível compreender que embora tenha ocorrido avanços significativos no rompimento do preconceito, este ainda representa um desafio no paradigma da atenção psicossocial, demandando do profissional, muitas vezes, tempo, dedicação e persistência.

Percebeu-se que os profissionais permanecem encontrando barreiras na sociedade, nos familiares ou mesmo nos próprios profissionais da rede que lidam com esses portadores, mostrando que ainda há muito a melhorar na efetivação das políticas públicas existentes no país.

Com esse estudo, entendeu-se, portanto, que quando existe vontade política e determinação, os objetivos fluem e se efetivam. Assim, recomenda-se a leitura 
desse artigo para gestores, profissionais, estudantes e população em geral, para que, definitivamente possa-se avançar no processo de reforma psiquiátrica, tão almejado nos últimos anos.

\section{REFERÊNCIAS}

1. Hirdes AA. Reforma psiquiátrica no Brasil: uma (re) visão. Universidade Luterana do Brasil, Unidade Universitária de Gravataí. Ciênc Saúde Coletiva; 2009 jan-fev;14(1):297305.

2. Amarante P. Loucos pela vida: a trajetória da reforma psiquiátrica no Brasil. 2 ${ }^{\mathrm{a}}$ ed. Rio de Janeiro (RJ): Fiocruz; 2010.

3. Ministério da Saúde (BR). Coordenação Geral de saúde Mental. Reforma psiquiátrica e política de saúde mental no Brasil. Documento apresentado a Conferência Regional de Reforma dos Serviços de Saúde Mental: 15 anos depois de Caracas. Brasília (DF): OPAS; 2005.

4. Delgado PGO, Ministério da Saúde (BR), Conferência Nacional de Saúde Mental 3. 2005. [Acesso nov. 2009]. Disponível em http://conselho.saude.gov.br/comissao/ saude_mental/apresentacao.htm.

5. Spadini LS, Souza MCBM . A doença mental sob o olhar de pacientes e familiares. Rev Esc Enferm USP. 2006 [Acesso em: 2010 out 21];40(1):123-7. Disponível em: http://www.scielo.br/pdf/reeusp/v40n1/a17v40n1.pdf.

6. Amarante P. Saúde mental e atenção psicossocial. $2^{\underline{a}}$ ed. Rio de Janeiro (RJ): Fundação Oswaldo Cruz; 2008.

7. Ferreira OS, Luis MAV. Percebendo as facilidades e dificuldades na implantação de serviços abertos em álcool e drogas. Revista Texto e Contexto. 2004;13(2).

8. Ministério da Saúde (BR). Programa permanente de formação de recursos humanos para a reforma psiquiátrica. [Acesso em: 2010 set 20]. Disponível em: http://portal.saude.gov.br/portal/saude/visualizar texto.cfm ?idtxt=33883.

9. Bardin L. Análise de conteúdo. Lisboa: Editora 70; 2008.

10. Conselho Nacional de Saúde. Regimento da IV Conferencia Nacional de Saúde Mental Intersetorial. [Acesso em: 2010 ago 10]. Disponível em: http://conselho.saude.gov.br/web_saudemental/doc/regim ento.pdf.

11. Delgado PG. A nova fronteira intersetorial ainda está por ser conquistada. Rev Radis. 2010 set;(97):18.

12. Sassaki RK. Inclusão: construindo uma sociedade para todos. $4^{\mathrm{a}}$ ed. Rio de Janeiro (RJ): WVA; 2002.

13. Waldow VR. Cuidado humano: o resgate necessário. $3^{\text {a }}$ ed. Porto Alegre (RS): Saga Luzato; 2001.

14. Figueiredo VV, Rodrigues MMP. Atuação do psicólogo nos CAPS do estado do Espírito Santo. Rev Psic Est. 2004 [acesso em: 2010 set 20];9(2) Disponível em: http://www.scielo.br/scielo.php?pid=S1413$73722004000200004 \&$ script=sci_arttext.

15. UNESCO. Declaração de Salamanca e linha de ação sobre necessidades educativas especiais. Brasília (DF): CORDE; 1994

16. Mori NNR. Alunos Especiais inseridos em classes regulares. In: Marquezini MC, organizador. Inclusão. Londrina (PR): EDUEL; 2003.

17. Freitas $\mathrm{SN}$. A formação de professores na educação inclusiva: construindo a base de todo o processo. In Rodrigues D, organizador. Inclusão e educação: doze olhares sobre a educação inclusiva. São Paulo (SP): SUMMUS; 2006.

18. Ministério da Saúde (BR). Estatuto da criança e do adolescente. 3a ed. Brasília (DF): MS; 2008. Série E. Legislação de Saúde.

19. Goldberg J. Reabilitação como processo - O Centro de Atenção Psicossocial - CAPS. In: PITTA, A. Reabilitação psicossocial no Brasil. 2 $2^{\underline{a}}$ ed. São Paulo (SP): Editora Hucitec; 2001.

20. Cirilo LS. Novos Tempos: saúde mental, CAPS e cidadania no discurso de usuários e familiares. [Dissertação]. Campina Grande (PB): Universidade Estadual da Paraíba, Programa de Pós-Graduação em Saúde Coletiva; 2006.

\section{Endereço para correspondência}

Elisangela Braga de Azevedo Rua Pedro Soares da Silva 55 Campina Grande/PB - CEP 58411-150

Telefone: +5583 33155161

E-mail: elisaaz@terra.com.br 